Acknowledgements: Muriel Herasse played a major role in collecting the missing data of the cohort.

We thank Julien Labreuche (biostatistician, CHU-Lille) for the help in the statistical analysis.

Disclosure of Interests: None declared

DOI: 10.1136/annrheumdis-2021-eular.1092

\section{OP0285 COVID-19 HOSPITALIZATIONS, ICU ADMISSION, AND DEATH AMONG PATIENTS WITH IMMUNE MEDIATED INFLAMMATORY DISEASES (IMID) - A POPULATION- BASED STUDY}

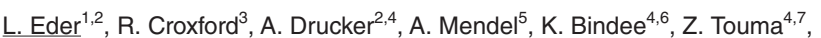
R. Cook $^{8}$, S. Johnson ${ }^{4,7}$, S. Bernatsky ${ }^{5}$, N. Haroon ${ }^{1,7}$, J. Widdifield ${ }^{9,10}$.

${ }^{1}$ University of Toronto, Medicine and Institute of Medical Science, Toronto, Canada; ${ }^{2}$ Women's College Research Institute, Medicine, Toronto, Canada; ${ }^{3}$ ICES, NA, Toronto, Canada; ${ }^{4}$ University of Toronto, Medicine and Health Policy Management and Evaluation, Toronto, Canada; ${ }^{5}$ Mc Gill University, Medicine, Montreal, Canada; ${ }^{6}$ Sinai Health System, Medicine, Toronto, Canada; ${ }^{7}$ Toronto Western Hospital, Medicine, Toronto, Canada; ${ }^{8}$ University of Waterloo, Biostatistics, Waterloo, Canada; ${ }^{9}$ University of Toronto, Institute of Health Policy Management and Evaluation, Toronto, Canada; ${ }^{10}$ Sunnybrook Research Institute, Medicine, Toronto, Canada

Background: It remains unclear whether patients with IMID are at greater risk for severe COVID-19.

Objectives: To investigate the risk of COVID-19 hospitalizations and their outcomes in patients with IMID compared with matched non-IMID patents from the general population.

Methods: A population-based, matched cohort study was conducted in adults living in Ontario, Canada using health administrative data. Ten cohorts of the following IMID were assembled: rheumatoid arthritis, psoriasis, psoriatic arthritis, ankylosing spondylitis, systemic autoimmune rheumatic diseases (SARDs, including systemic lupus, systemic sclerosis, Sjogren's, myositis), multiple sclerosis (MS), iritis, inflammatory bowel disease, polymyalgia rheumatica (PMR), and vasculitis (including giant cell arteritis and other types of vasculitidies). Each patient was matched with 5 non-IMID comparators based on age, sex, area of residence and living in long-term care (LTC). Patients who were admitted to hospital from January $1^{\text {st }}$ to July $31^{\text {th }}, 2020$ and had ICD-10 COVID-19 diagnosis codes (U07.2 or U07.1) were identified. Among those with COVID-19 hospitalizations, we determined those with admissions to intensive care unit or required mechanical ventilation or died in hospital ('complicated hospitalization'). Age-sex-standardized rates were compared between IMID and non-IMID patients and risk factors for hospitalizations were identified by multivariable logistic regression analysis.

Results: In total, 493,499 IMID (417 hospitalized) and 2,466,946 non-IMID patients (1,519 hospitalized) were assessed. The age-sex-standardized rate of COVID-19 hospitalization was higher in IMID (6.4 per 10,000, 95\% confidence interval $(\mathrm{Cl}) 5.8,7.2$ ) versus non-IMID patients ( 4.8 per $100,000,95 \% \mathrm{Cl} 4.5,5)$. The highest rates of hospitalizations were found in vasculitis $(18 / 10,000)$, MS $(16.7 / 10,000)$ and PMR $(10.1 / 10,000)$. IMID diagnosis was associated with $37 \%$ higher risk of being hospitalized for COVID-19 (Odds Ratio (OR) $1.37,95 \% \mathrm{Cl}$ $1.23,1.53$ ) (Figure 1). This risk was slightly attenuated after adjusting for sociodemographic factors and comorbidities but remained elevated by $23 \%$ compared to non-IMID (OR 1.23, 95\% Cl 1.10, 1.37). The risk for hospitalizations was increased in RA, vasculitis, SARDs, PsA, MS and iritis (Figure 1). Risk factors for COVID-19 hospitalizations included older age, male sex, lower income, multimorbidity and living in long-term care (Table 1). The risk for complicated COVID19 hospitalizations was higher by $21 \%$ in IMID patients (OR $1.21,95 \% \mathrm{Cl} 1.02$, $1.43)$, however, this association was attenuated after adjustment for demographics and comorbidities (OR 1.08).

Table 1. Risk Factors for COVID-19 Hospitalizations in IMIDs vs. non-IMIDs

\begin{tabular}{|c|c|c|}
\hline Variable & OR & $95 \% \mathrm{Cl}$ \\
\hline IMIDs vs. Non-IMID & 1.23 & $1.10,1.37$ \\
\hline Age (10 yrs) & 1.49 & $1.44,1.54$ \\
\hline Sex: Female & 0.68 & $0.62,0.75$ \\
\hline Long term care resident & 8.28 & $7.32,9.37$ \\
\hline ADG: $5-9$ vs. $0-4$ & 1.45 & $1.22,1.71$ \\
\hline $10-14$ vs. $0-4$ & 2.26 & $1.92,2.67$ \\
\hline $15+$ vs. $0-4$ & 3.23 & $2.73,3.82$ \\
\hline \multicolumn{3}{|l|}{ Income (quintile) } \\
\hline Quintile 2 vs. 1 & 0.82 & $0.73,0.93$ \\
\hline Quintile 3 vs. 1 & 0.76 & $0.67,0.86$ \\
\hline Quintile 4 vs. 1 & 0.56 & $0.48,0.64$ \\
\hline Quintile 5 vs. 1 & 0.46 & $0.40,0.54$ \\
\hline Urban vs. rural & 4.33 & $3.32,5.67$ \\
\hline
\end{tabular}

ADG - Aggregated Diagnosis Groups
Conclusion: Patients with IMID were at higher risk of being hospitalized with COVID-19 and for having complicated hospitalizations. Hospitalization risk was partially independent of their comorbid conditions.

Acknowledgements: The study is supported by ICES, which is funded by an annual grant from the Ontario Ministry of Health and Long-Term Care (MOHLTC) Parts of this material are based on data and information compiled and provided by MOHLTC and the Canadian Institute for Health Information. The opinions results and conclusions reported in this paper are those of the authors and are independent of the funding or data sources; no endorsement is intended or should be inferred.

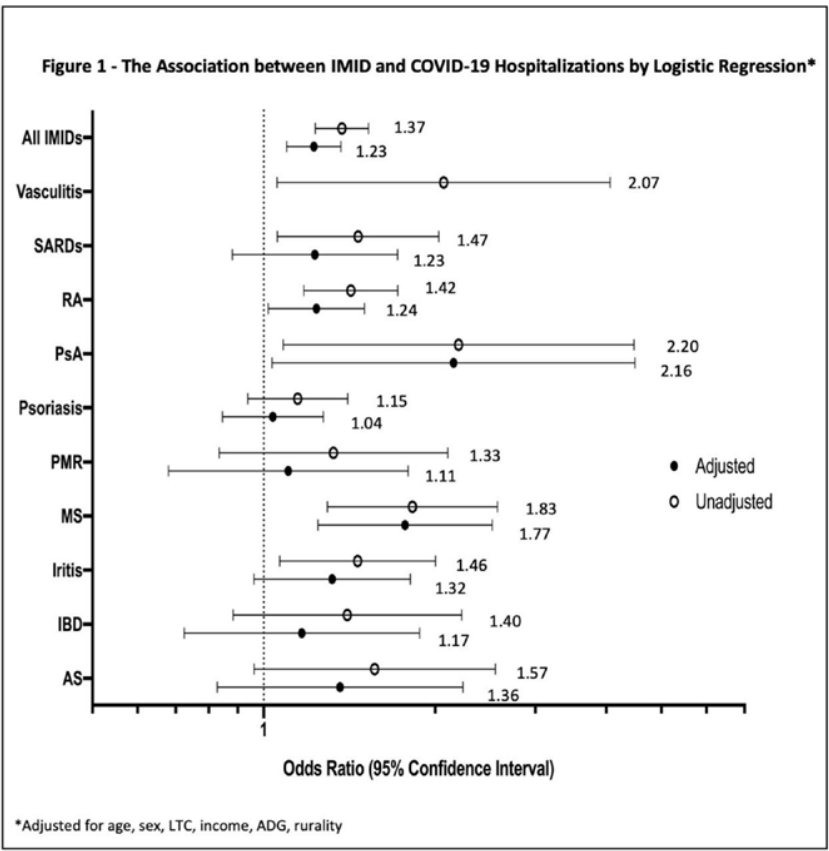

Disclosure of Interests: None declared DOI: 10.1136/annrheumdis-2021-eular.1466

\section{OP0286 CHARACTERISTICS ASSOCIATED WITH SEVERE COVID-19 OUTCOMES IN SYSTEMIC LUPUS ERYTHEMATOSUS (SLE): RESULTS FROM THE COVID- 19 GLOBAL RHEUMATOLOGY ALLIANCE (COVID-19 GRA)}

M. F. Ugarte-Gil ${ }^{1,2}$, G. S. Alarcon ${ }^{3,4}$, A. Seet ${ }^{5}$, Z. Izadi $^{5,6}$, C. Reategui Sokolova $^{2,7}$, A. E. Clarke ${ }^{8}$, L. Wise ${ }^{9}$, G. Pons-Estel ${ }^{10}$, M. J. Santos ${ }^{11}$, S. Bernatsky ${ }^{12}$, L. Mathias ${ }^{9}$, N. Lim ${ }^{9}$, J. Sparks ${ }^{13}$, Z. Wallace ${ }^{14}$, K. Hyrich ${ }^{15}$, A. Strangfeld ${ }^{16}$, L. Gossec ${ }^{17}$, L. Carmona ${ }^{18}$, E. Mateus ${ }^{19}$, S. LawsonTovey $^{20}$, L. Trupin ${ }^{5}$, S. Rush ${ }^{5}$, G. Schmajuk ${ }^{5}$, P. Katz ${ }^{5}$, L. Jacobsohn ${ }^{5}$, S. Al Emadi $^{21}$, E. Gilbert ${ }^{22}$, A. Duarte-Garcia ${ }^{23}$, M. Valenzuela-Almada ${ }^{24}$, T. Hsu ${ }^{25}$ K. D'silva ${ }^{26}$, N. Serling-Boyd ${ }^{27}$, P. Dieudé ${ }^{28}$, E. Nikiphorou ${ }^{29}$, V. Kronzer ${ }^{30}$, N. Singh ${ }^{31}$, B. Wallace ${ }^{32}$, A. Akpabio ${ }^{33}$, R. Thomas $^{34}$, S. Bhana ${ }^{35}$, W. Costello ${ }^{36}$, R. Grainger ${ }^{37}$, J. Hausmann ${ }^{38}$, J. Liew ${ }^{39}$, E. Sirotich ${ }^{40}$, P. Sufka ${ }^{41}$, P. Robinson ${ }^{42}$, P. Machado ${ }^{43}$, M. Gianfrancesco ${ }^{5}$, J. Yazdany ${ }^{44}$ on behalf of COVID-19 Global Rheumatology Alliance. ${ }^{1}$ Universidad Científica del Sur, School of Medicine, Lima, Peru; ${ }^{2}$ Hospital Nacional Guillermo Almenara Irigoyen, EsSalud, Rheumatology, Lima, Peru; ${ }^{3}$ University of Alabama at Birmingham, Department of Medicine, Birmingham, Alabama, United States of America; ${ }^{4}$ Universidad Peruana Cayetano Heredia, Facultad de Medicina, Lima, Peru; ${ }^{5}$ University of California, Division of Rheumatology, Department of Medicine, San Francisco, United States of America; ${ }^{6}$ University of California, Department of Epidemiology and Biostatistics, San Francisco, United States of America; ${ }^{7}$ Universidad San Ignacio de Loyola, Unidad de Investigación para la Generación y Síntesis de Evidencias en Salud, Lima, Peru; ${ }^{8}$ Cumming School of Medicine. University of Calgary, Division of Rheumatology Department of Medicine, Calgary, Canada; ${ }^{9}$ University of Southern California, Division of Rheumatology, Department of Internal Medicine, Los Angeles, CA, United States of America; ${ }^{10}$ Centro Regional de Enfermedades Autoinmunes y Reumáticas (GO-CREAR), Centro Regional de Enfermedades Autoinmunes y Reumáticas (GO-CREAR), Rosario, Argentina; ${ }^{11}$ Instituto de Medicina Molecular, Faculdade de Lisboa, Rheumatology Department, Hospital Garcia de Orta, Almada and Rheumatology Research Unit, Lisbon, Portugal; ${ }^{12}$ Mc Gill University Health Centre, Divisions of Rheumatology and Clinical Epidemiology, 